\title{
Altered Unfolded Protein Response Is Implicated in the Age-Related Exacerbation of Proteinuria-Induced Proximal Tubular Cell Damage
}

\author{
Naoko Takeda, ${ }^{*}$ Shinji Kume, ${ }^{*}$ Yuki Tanaka, ${ }^{*}$ Yoshikata Morita, ${ }^{*}$ Masami Chin-Kanasaki, ${ }^{*}$ Hisazumi Araki, ${ }^{*}$ Keiji Isshiki, \\ Shin-ichi Araki, ${ }^{*}$ Masakazu Haneda, ${ }^{\dagger}$ Daisuke Koya, ${ }^{\ddagger}$ Atsunori Kashiwagi, ${ }^{*}$ Hiroshi Maegawa, ${ }^{*}$ and Takashi Uzu*
}

From the Department of Medicine, ${ }^{*}$ Shiga University of Medical Science, Otsu; the Department of Medicine, ${ }^{\dagger}$ Asahikawa Medical University, Asahikawa; and the Division of Diabetology and Endocrinology, ${ }^{\ddagger}$ Kanazawa Medical University, Uchinada, Japan

Accepted for publication

May 14, 2013.

Address correspondence to Takashi Uzu, M.D., Ph.D., Department of Medicine, Shiga University of Medical Science, Tsukinowa-Cho, Seta, Otsu, Shiga 520-2192, Japan. E-mail: takazu@ belle.shiga-med.ac.jp.

\begin{abstract}
Aging is a dominant risk factor for end-stage renal disease. We analyzed the mechanism involved in agerelated exacerbation of proteinuria-induced proximal tubular cell (PTC) damage by focusing on endoplasmic reticulum-related unfolded protein response (UPR). After equal-degree induction of proteinuria in 24-month-old (aged) and 3-month-old (young) mice by intraperitoneal free fatty acid-bound albumin overload, tubulointerstitial lesions were more severe in aged than in young mice. In aged PTCs, proteinuria-induced cell-adaptive UPR resulting from induction of the molecular chaperone BiP was significantly suppressed, whereas proapoptotic UPR with CHOP overexpression was enhanced. Treatment with the exogenous molecular chaperone tauroursodeoxycholic acid (TUDCA) ameliorated proteinuriainduced tubulointerstitial lesions and PTC apoptosis in aged mice. Among the three UPR branches, alterations in the inositol-requiring $1 \alpha$ (IRE1 $\alpha$ ) pathway, but not the activating transcription factor 6 or PERK pathway, were associated with impaired BiP induction in aged kidneys. Moreover, siRNA-mediated suppression of BiP and IRE1 $\alpha$ exacerbated free fatty acid-bound albumin-induced apoptosis in cultured PTCs, whereas siRNA-mediated CHOP suppression ameliorated apoptosis. Finally, proteinuria-induced BiP induction in PTCs was diminished in kidney specimens from elderly patients. These results indicate that maladaptive UPRs are involved in proteinuria-induced tubulointerstitial lesions exacerbation in aged kidneys, and that supplementation of chaperones may be used to treat elderly patients with persistent proteinuria. These results should improve understanding of cell vulnerability in aged kidneys. (Am J Pathol 2013, 183: 774-785; http://dx.doi.org/10.1016/j.ajpath.2013.05.026)
\end{abstract}

Improvements in life expectancy have increased the populations of elderly people worldwide. Age-related diseases, however, such as metabolic and vascular diseases, cancers, neurodegenerative diseases, and kidney diseases requiring renal replacement therapy, may reduce quality of life. ${ }^{1-3}$ Strategies are therefore necessary to close the gap between life expectancy and healthy life expectancy. Although organisms have evolved systems to cope with cytotoxic stress, the normal aging process often alters these systems, leading to stress susceptibility in organs and poorer health in older individuals. ${ }^{4,5}$ Identifying the molecular mechanisms that underlie age-dependent cellular vulnerability to stress should therefore lead to a better and healthier life for elderly people.
Aging is an independent risk factor for end-stage renal disease. $^{6,7}$ In patients with glomerular diseases, persistent and treatment-resistant proteinuria is a leading cause of end-stage renal disease, and the severity of proteinuriainduced tubulointerstitial lesions is more strongly correlated with renal prognosis than are glomerular lesions themselves. ${ }^{8}$ Thus, the poor renal outcomes observed in elderly patients with proteinuria suggest that renal proximal tubular cells (PTCs) in aged kidney are especially vulnerable to proteinuria-induced renal toxicity.

Supported in part by the Uehara Memorial Foundation (S.K.) and by the Fourth Annual Research Award Grant of the Japanese Society of AntiAging Medicine (D.K.). 
Identification of the mechanisms underlying the agedependent susceptibility of PTCs could lead to new therapeutic options that improve renal outcomes in elderly patients with persistent proteinuria.

The endoplasmic reticulum (ER) is a cellular organelle that maintains intracellular protein homeostasis by facilitating protein folding. ${ }^{9,10}$ In some pathological conditions, normal protein folding is inhibited, leading to the accumulation of misfolded and unfolded proteins that induce cellular toxicity. ${ }^{11}$ Cells have accordingly evolved intricate signaling networks to respond to the accumulation of unfolded proteins and to expand their protein-processing capacity. This response, known as ER stress, is a cell defense system marked by the activation of a group of complex signaling pathways called the unfolded protein response (UPR). The UPR consists of three branches: the inositol-requiring $1 \alpha$ (IRE1 $\alpha$ ), activating transcription factor 6 (ATF6), and protein kinase RNA-like endoplasmic reticulum kinase (PERK) pathways. ${ }^{9-11}$ These UPR pathways work coordinately to expand the capacities of ER protein folding and stress resistance by transcriptionally up-regulating endogenous molecular chaperones such as $78-\mathrm{kDa}$ glucoseregulated protein [GRP-78; here referred to as immunoglobulin heavy chain-binding protein (BiP)], calreticulin, and 94-kDa glucose-regulated protein (GRP-94). ${ }^{12,13}$ In cells exposed to unrecoverable and prolonged stress, however, these UPR pathways enhance apoptotic cell death via overexpression of proapoptotic transcriptional factors such as C/EBP homologous protein (CHOP). ${ }^{14-16}$ Thus, the UPR has been recognized as an intracellular adaptive mechanism that regulates cell fate under some stress conditions. Although up-regulation of the UPR has been observed in several experimental kidney disease models, ${ }^{17-22}$ the relationships among the UPR, age-related cell vulnerability, and kidney diseases have remained unclear.

We hypothesized that the normal aging process alters proteinuria-induced UPR in PTCs, leading to severe PTC damage in aged kidneys. To test this hypothesis, we examined the effects of aging both on the UPR and on PTC damage in a mouse proteinuric kidney disease model and in kidney specimens from patients with proteinuria.

\section{Materials and Methods}

\section{Antibodies and Reagents}

Rabbit monoclonal antibody to cleaved caspase 3, rabbit monoclonal antibody to phosphorylated PERK, rabbit monoclonal antibody to PERK, mouse monoclonal antibody to $\mathrm{CHOP}$, rabbit monoclonal antibody to $\mathrm{BiP}$, rabbit polyclonal antibody to GRP94, rabbit monoclonal antibody to calreticulin, and rabbit monoclonal antibody to IRE1 $\alpha$ were from Cell Signaling Technology (Danvers, MA). Mouse monoclonal antibody to ATF6 was from Imgenex (San Diego, CA), and rabbit polyclonal antibody to XBP1 was from Santa Cruz Biotechnology (Santa Cruz, CA).
Biotinylated Lotus tetragonolobus (asparagus-pea) lectin (LTL) was from Vector Laboratories (Burlingame, CA). Sodium palmitate was from Sigma-Aldrich (St. Louis, MO), and tauroursodeoxycholic acid (TUDCA) was from Calbiochem-EMD Millipore (Billerica, MA).

\section{Animal Models}

All procedures were performed in accordance with the guidelines of the Research Center for Animal Life Science of Shiga University of Medical Science.

\section{FFA-Bound Albumin Overload Model in Aged Mice}

Male C57BL/6 mice were obtained at age 8 weeks and were maintained on a 12-hour light/dark cycle and provided food and water until reaching the ages of 3 months (young) or 24 months (aged). Young $(n=8)$ and aged $(n=5)$ mice received daily intraperitoneal bolus injections of $0.3 \mathrm{~g}$ per 30 g body weight of free fatty acid (FFA)-bound bovine serum albumin (Sigma-Aldrich) diluted in sterile phosphatebuffered saline (PBS) for four consecutive days; as a control, young $(n=5)$ and aged $(n=4)$ mice were injected with an equal volume of sterile PBS for four consecutive days. After the injections on day 4, the mice were anesthetized and sacrificed, and blood and kidney samples were collected as described previously. ${ }^{23}$ Serum cystatin $\mathrm{C}$ was measured using cystatin C (mouse) ELISA kits (Alexis Biochemicals; Enzo Group, Basel, Switzerland) as described previously. ${ }^{24}$ Urinary protein concentration was measured using the Bradford method, and urinary creatinine concentration was measured using a photometric assay based on the Jaffe reaction (Wako creatinine kit; Wako Pure Chemical Industries, Osaka, Japan). Urinary protein excretion levels were calculated as the ratio of protein to creatinine.

\section{FFA-Bound Albumin Overload Model in Aged Mice With or Without TUDCA Treatment}

Aged mice were given twice daily intraperitoneal bolus injections of $250 \mathrm{mg} / \mathrm{kg}$ TUDCA ( $500 \mathrm{mg} / \mathrm{kg}$ per day) diluted in sterile PBS or an equal volume of PBS. ${ }^{25,26}$ Three days later, the mice were given daily intraperitoneal bolus injections of $0.3 \mathrm{~g}$ per $30 \mathrm{~g}$ body weight FFA-bound albumin diluted in sterile PBS or an equal volume of sterile PBS, in addition to TUDCA or PBS, for 4 days. Six young and four aged mice were treated with bovine serum albumin, and four aged mice were treated with both bovine serum albumin and TUDCA. After the injections on day 4, the mice were anesthetized and sacrificed as described previously. ${ }^{23}$

\section{Histological and Immunohistochemical Analyses}

Fixed kidneys embedded in paraffin were sectioned at 3$\mu \mathrm{m}$ thickness and were stained with H\&E to evaluate PTC damage. Five nephrologists masked to age and treatment 
group and experienced in renal histopathology independently quantified and rated the morphological changes in the different morphological compartments. PTC damage was graded as follows: 0 , none; 1 , minor; 2 , moderate; 3 , severe; and 4, most severe. TUNEL staining was performed with a TACS 2 TdT kit (Trevigen, Gaithersburg, MD), and TUNEL-positive and TUNEL-negative cells were counted in 10 randomly selected areas of the kidney cortex. Sections were also immunohistochemically stained with a rabbit monoclonal antibody to $\mathrm{BiP}$, as described previously. ${ }^{23}$

\section{Protein Extraction and Western Blot Analysis}

Renal cortex samples were homogenized in ice-cold lysis buffer containing $150 \mathrm{mmol} / \mathrm{L} \mathrm{NaCl}, 50 \mathrm{mmol} / \mathrm{L}$ Tris-HCl (pH 8.0), $0.1 \%$ SDS, $1 \%$ Nonidet P-40, and protease inhibitor cocktail (Roche Diagnostics, Lewes, UK; Mannheim, Germany) and clarified by centrifugation (15 minutes, $15,000 \times g$ ). Samples were resolved by $10 \%$ SDSPAGE and transferred to Immobilon polyvinylidene fluoride membranes (EMD Millipore). The membranes were incubated with antibodies and the blots were visualized using an enhanced chemiluminescence detection system (PerkinElmer, Waltham, MA), as described previously. ${ }^{23}$

\section{RNA Extraction and $q P C R$}

Total RNA samples were isolated from kidneys and cultured renal cells, and cDNA was synthesized as described previously. ${ }^{23}$ iQ SYBR Green Supermix (Bio-Rad Laboratories, Hercules, CA) was used for quantitative real-time PCR (qPCR) with an ABI Prism 7500 sequence detection system (Life Technologies, Carlsbad, CA). mRNA expression levels were quantified using the standard curve method. Analytical data were adjusted, with the expression level of $\beta$-actin mRNA as an internal control. Primer sequences for amplification were as follows: Ngal forward 5'-CCCTGTATGGAAGAACCAAGGA-3' and reverse $5^{\prime}$-CGGTGGGGACAGAGAAGATG- $3^{\prime}$; Kim-1 forward 5'-GCTACAGGAAGACCCACGACTATTT- $3^{\prime}$ and reverse 5'-GATGTTGGAGGAGTGGAGGTAGAG- $3^{\prime}$; and $\beta$-actin forward $5^{\prime}$ CGTGCGTGACATCAAAGAGAA- $3^{\prime}$ and reverse $5^{\prime}$-TGGATGCCACAGGATTCCAT-3'.

\section{Cell Culture}

Mouse renal PTCs (mProx24) were cultured as described previously. ${ }^{23,27-29}$ In brief, cells were cultured in Dulbecco's modified Eagle's medium containing $10 \%$ fetal calf serum, $100 \mathrm{U} / \mathrm{mL}$ penicillin, and $100 \mu \mathrm{g} / \mathrm{mL}$ streptomycin at $37^{\circ} \mathrm{C}$ and $5 \% \mathrm{CO}_{2}$. Subconfluent cells were starved by incubation with $0.2 \%$ fetal calf serum-Dulbecco's modified Eagle's medium for 12 hours, followed by stimulation with $150 \mu \mathrm{mol} / \mathrm{L}$ of palmitate bound to bovine serum albumin $(0.15 \%)$ for 9 hours. $^{23,27-29}$ To assess the effects of
TUDCA, cells were pretreated with $1 \mathrm{mmol} / \mathrm{L}$ of TUDCA for 60 minutes before stimulation with palmitate.

\section{siRNA Transfection}

Cultured PTCs $\left(1.6 \times 10^{6}\right)$ were seeded in six-well plates and incubated for 24 hours. BiP, CHOP, and IRE1 $\alpha$ were silenced by incubation with specific siRNAs (Dharmacon SMARTpool reagent; Thermo Scientific, Pittsburgh, PA), as well as with the negative control siRNA (nontargeting siRNA; Thermo Scientific). Each Dharmacon ONTARGETplus SMARTpool siRNA reagent was a mixture of four different siRNAs. The sequences were siBiP $5^{\prime}$ GGAUUGAAAUUGAGUCCUU- ${ }^{\prime}$, 5'-GAAACUCCGGCGUGAGGUA- $3^{\prime}$, 5'-GCAUCACGCCGUCGUAUGU- $3^{\prime}$ and $5^{\prime}$-GAUCUACUCGAAUUCCAAA-3'; siCHOP $5^{\prime}$ CAACAGAGGUCACACGCAC- ${ }^{\prime}$, 5'-GCACCAAGCAUGAACAGUG-3', 5'-GAGCAAGGAAGAACUAGGA-3' and $5^{\prime}$-GAAACAGAGUGGUCAGUGC-3'; and siIRE $1 \alpha$ $5^{\prime}$-GAAAGGUGGUGCACAUCAA- $3^{\prime}, \quad 5^{\prime}$-UGAACUACUUGCGGAAUUA- $3^{\prime}$, 5'-CGUCAUUGCUCGUGAAUUG- $3^{\prime}$ and $5^{\prime}$-UGACGAAACUUCCCUUUAC- ${ }^{\prime}$. Cells were transfected with $100 \mathrm{nmol} / \mathrm{L}$ of each siRNA using DharmaFECT 4 transfection reagent (Thermo Scientific) and were incubated for 24 hours in medium containing $0.2 \%$ fetal calf serum. Transfected cells were incubated with $0.2 \%$ fetal calf serum-Dulbecco's modified Eagle's medium for 12 hours and then were treated with $150 \mu \mathrm{mol} / \mathrm{L}$ palmitateconjugated albumin for an additional 9 hours.

\section{qPCR Analysis of XBP1 mRNA Splicing}

To evaluate XBP1 splicing, mouse XBP1 primers were designed to span the 26-bp intron splicing site: forward $5^{\prime}$-TGAGAACCAGGAGTTAAGAACACGC- $3^{\prime}$ and reverse $5^{\prime}$-TTCTGGGTAGACCTCTGGGAGTTCC- $3^{\prime}$. These primers yielded PCR products of $326 \mathrm{bp}$ for unspliced and $300 \mathrm{bp}$ for spliced XBP1. The PCR reaction was performed as described previously, ${ }^{30}$ with the amplified products separated by electrophoresis on $3 \%$ agarose gels and visualized by ethidium bromide staining.

Immunohistochemical Assessment of BiP Expression in Kidney Specimens Obtained from Patients with or without Overt Proteinuria

Human kidney biopsy materials were collected after the receipt of informed consent from the patients, with the protocol approved by the Scientific-Ethical Committee of Shiga University of Medical Science, and in adherence with the Declaration of Helsinki guidelines regarding ethical principles for medical research involving human subjects. Paraffin-embedded kidney sections used for this study were those remaining after a diagnosis of proteinuria induced by glomerular disease. Young adults were aged less than 30 years, and elderly adults were 
aged more than 70 years. Nonovert proteinuria was defined as $<0.5 \mathrm{~g}$ urine total protein per gram creatinine $(\mathrm{g} / \mathrm{gCre})$, and overt proteinuria as urine total protein of $>1 \mathrm{~g} / \mathrm{gCre}$. The formalin-fixed human kidney samples were incubated with antibody to $\mathrm{BiP}$ and with biotinylated LTL, ${ }^{31}$ with the latter developed using an $\mathrm{ABC}-\mathrm{AP}$ regimen (Vectastain ABC-AP kit; Vector Laboratories, Burlingame, CA). BiP-positive cells were counted in 10 randomly selected areas.

\section{Statistical Analysis}

Analysis of variance with subsequent Fisher's test was used to determine the significance of differences in multiple comparisons. Pearson's correlation coefficients were calculated to investigate the association among indicated parameters. A $P$ value of $<0.05$ was considered statistically significant. Data are expressed as means \pm SEM.

\section{Results}

\section{Proteinuria-Induced PTC Damage Is Exacerbated in Aged Kidneys}

To assess the effects of aging on the progression of proteinuria-induced tubulointerstitial lesions, proteinuria was experimentally induced in both young ( 3 months old) and aged (24 months old) mice by intraperitoneal FFAbound albumin overload, an established mouse model used to assess proteinuria-induced tubulointerstitial lesions. ${ }^{23,32}$ We first confirmed that the normal aging process caused mild damage to PTCs, as indicated by histological alterations (Figure 1, A and B), elevated serum cystatin C concentrations (Figure 1C), and elevated expression of neutrophil gelatinase-associated lipocalin (Ngal) mRNA (Figure 1D). The normal aging process also resulted in significant induction of apoptosis, as indicated by increases in TUNEL-positive cells (Figure 1, A and E). In young mice, FFA-bound albumin overload significantly elicited histological PTC damage, including diffuse tubular cell vacuolation, tubular cell flattening, and tubular lumen dilation (Figure 1, A and B), increased Ngal mRNA expression (Figure 1D), and apoptosis, as indicated by increases in TUNEL-positive cells and cleavage of caspase 3 (Figure 1A, E-G). We also observed significant exacerbation of FFA-bound albumin overload-induced PTC damage and apoptosis in aged mice (Figure 1, A-G), although the PTCs of both young and aged mice were exposed to equal degrees of the proteinuria induced by FFA-bound albumin overload (Figure $1 \mathrm{H})$. Thus, both proteinuria in young mice and the normal aging process caused mild PTC damage, whereas proteinuria in aged mice led to severe PTC damage, suggesting that PTCs in aged kidneys are especially vulnerable to proteinuria.

\section{Proteinuria-Induced Chaperone Induction Is Diminished in Aged Kidneys}

We next examined the effects of proteinuria and the normal aging process on the UPR in the kidneys. Adaptive UPR leading to the increased expression of endogenous molecular chaperones is essential in protecting cells from
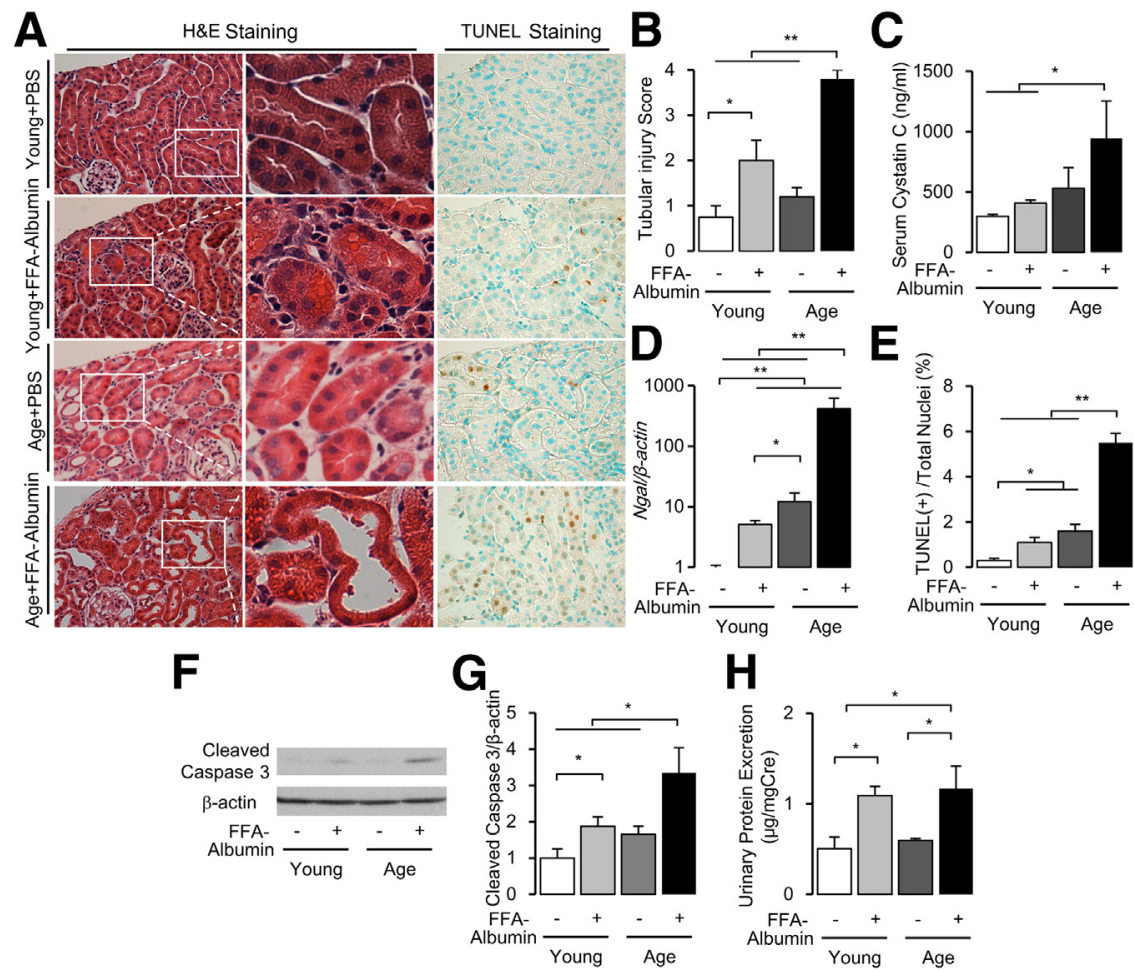

Figure 1 Aged mice develop more severe proteinuria-induced PTC damage than do young mice. A: H\&E staining and TUNEL staining of representative kidney sections from young mice injected with PBS (Young+PBS; $n=5$ ), young mice injected with FFA-bound albumin (Young +FFA-albumin; $n=8$ ), aged mice injected with PBS (Age+PBS; $n=4)$, and aged mice injected with FFA-bound albumin (Age+FFA-albumin; $n=5)$. Boxed regions correspond to the enlarged images in the next column. B: Tubular injury scores in H\&E-stained kidney sections from the four groups of mice. C: Serum cystatin C concentrations in the four groups of mice. D: Expression of $\mathrm{Ngal}$ mRNA in kidney samples from the four groups of mice. E: Quantitative analysis of TUNEL-positive cells in the kidney sections from the four groups of mice. F: Representative immunoblots of cleaved caspase 3 in protein samples from kidney of the four groups of mice, with $\beta$-actin as the internal loading control. G: Quantitative analysis of the ratios of cleaved caspase 3 to $\beta$-actin. $\mathbf{H}$ : Urinary protein excretion levels in the four groups of mice. Data were normalized relative to the results in the Young + PBS group. Data are expressed as means \pm SEM. ${ }^{*} P<0.05,{ }^{* *} P<0.01$. Original magnification, $\times 400$. 
cytotoxic stress, whereas prolonged or insufficient UPR leads to apoptotic cell death via CHOP overexpression. Both FFA-bound albumin overload in young mice and normal aging increased expression levels of endogenous molecular chaperones in the kidneys, such as BiP, calreticulin, and GRP94 (Figure 2, A-E). In contrast, FFA-bound albumin overload in aged mice failed to increase chaperone induction (Figure 2, A-E), but enhanced expression of the proapoptotic transcriptional factor CHOP (Figure 2, B and F). These results suggest that both proteinuria in young mice and the normal aging process led to adaptive UPR, whereas aging impaired proteinuria-induced adaptive UPR and enhanced ER-related apoptosis signaling.

Because expression levels of both $\mathrm{BiP}$ and $\mathrm{CHOP}$ are regulated by the three ER stress transducer pathways ATF6, PERK, and IRE $1 \alpha,{ }^{9-11}$ we assessed the activities of these pathways in the kidneys of four groups of mice. The activities of ATF6 and PERK were analyzed by assessing their cleavage and phosphorylation, respectively, and the activity of IRE1 $\alpha$ was determined by the splicing of X-box binding protein 1 (XBP1), a downstream molecule of IRE1 $\alpha$. Both proteinuria in young mice and normal aging significantly increased the splicing of XBP1 and the cleavage of ATF6, without affecting PERK activation (Figure 3, A-D). In aged mice, proteinuria significantly enhanced PERK phosphorylation and decreased XBP1 splicing (Figure 3, A, B, and D).

To determine the significance of the differential expression patterns of the three branches of the UPR, we analyzed the correlations between the activities of the branches and the expression levels of $\mathrm{BiP}$ and $\mathrm{CHOP}$. XBP1 splicing was positively correlated with $\mathrm{BiP}$ expression (Figure $3 \mathrm{E}$ ), and ATF6 cleavage and PERK phosphorylation were positively correlated with CHOP expression (Figure 3F). These results suggest that differences in the induction of the three independent UPR pathways lead to differences in cell fate that are dependent on circumstances and stresses in the kidneys, and that the IRE1 $\alpha-\mathrm{XBP} 1$ pathway plays the most important role in proteinuria-induced induction of molecular chaperones.

BiP and CHOP Are Essential for Stress Resistance and Apoptosis, Respectively, in Cultured PTCs Stimulated with Palmitate-Bound Albumin

To investigate whether proteinuria induced by FFA-bound albumin overload directly induces the UPR and apoptosis in PTCs of mice, we examined the UPR and apoptosis in cultured PTCs stimulated with palmitate-bound albumin (palmitate is a saturated FFA). ${ }^{23,27-29}$ Palmitate-bound
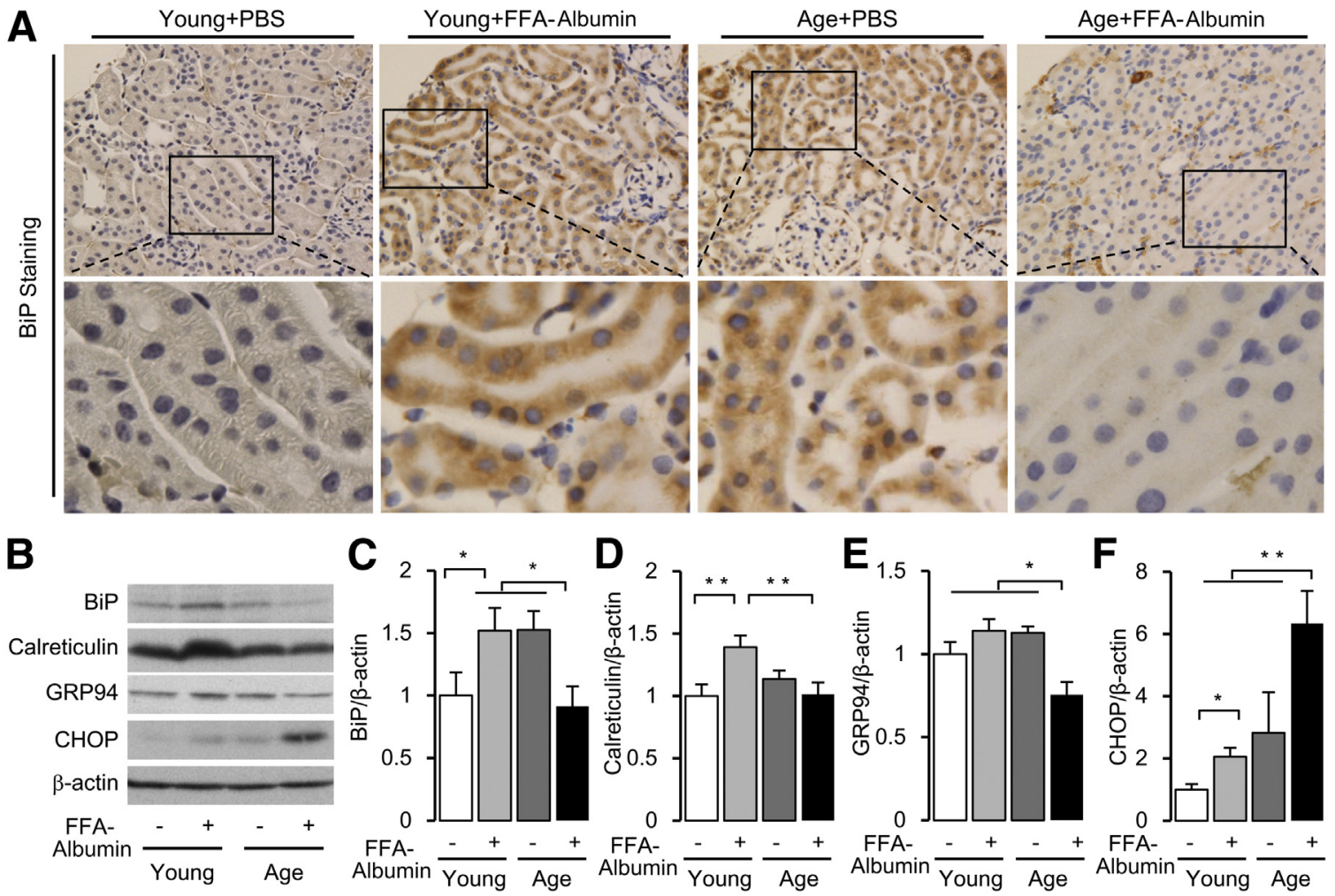

Figure 2 Impairment of proteinuria-induced chaperone induction in the PTCs of aged mice. A: Representative kidney sections immunostained with antibody to BiP in the same four groups of mice as for Figure 1. Boxed regions correspond to the enlarged images in the next row. B: Representative immunoblots for BiP, calreticulin, GRP94, CHOP, and $\beta$-actin in protein samples from kidneys of each group of mice, with $\beta$-actin as the internal loading control. C-F: Quantitative analysis of the ratios to $\beta$-actin of BiP (C), calreticulin (D), GRP94 (E), and CHOP (F). Data are expressed as means \pm SEM. ${ }^{*} P<0.05,{ }^{* *} P<0.01$. Original magnification, $\times 400$. 
albumin induced apoptosis of cultured PTCs, as determined by cleavage of caspase 3 (Figure 4, A and B), and induced the UPR, as indicated by increased PERK phosphorylation, XBP1 splicing, and expression of BiP and CHOP (Figure 4, $\mathrm{A}$ and $\mathrm{C}-\mathrm{F}$ ). However, pretreatment with the exogenous molecular chaperone TUDCA significantly ameliorated induction of the UPR and apoptosis by palmitate-bound albumin (Figure 4, A-F).

To assess the pathogenic significance of $\mathrm{BiP}$ suppression observed in the kidneys of aged mice injected with FFAbound albumin, we investigated the effects of BiP deficiency on palmitate-bound albumin-induced apoptosis in PTCs. Cultured PTCs transfected with BiP siRNA exhibited a reduction in expression of $\mathrm{BiP}$ and a significant increase in palmitate-bound albumin-induced apoptosis (Figure 4, G and $\mathrm{H}$ ). Even in PTCs lacking BiP expression, TUDCA inhibited palmitate-bound albumin-induced apoptosis (Figure 4, G and H).

To examine the role of CHOP induction in proteinuriainduced apoptosis, we investigated the effects of CHOP deficiency on palmitate-bound albumin-induced apoptosis in PTCs. Suppression of CHOP induction with CHOP siRNA significantly ameliorated palmitate-bound albumin-induced PTC apoptosis (Figure 4, I and J). Taken together, these results suggest that the balance between $\mathrm{BiP}$ and $\mathrm{CHOP}$ expression levels affects age-dependent cell vulnerability and apoptosis of PTCs exposed to FFA-bound albumin.
The IRE1 $\alpha$ Pathway Is Essential for BiP Expression in Cultured PTCs

Because $\mathrm{BiP}$ induction plays an important role in protecting cells against proteinuria, and because the activity of IRE1 $\alpha$ was positively correlated with BiP expression in animals, we further analyzed the roles of the IRE1 $\alpha$ pathway in proteinuria-induced $\mathrm{BiP}$ induction and apoptosis. Gene silencing of IRE1 $\alpha$ significantly inhibited palmitate-bound albumin-induced splicing of XBP1, as determined by immunoblotting, PCR analysis, and subsequent BiP induction (Figure 4, $\mathrm{K}-\mathrm{O}$ ), but it significantly enhanced cell apoptosis (Figure 4, P and Q). TUDCA, however, ameliorated palmitate-bound albumin-induced apoptosis, even in PTCs lacking IRE1 $\alpha$ (Figure 4, P and Q), in which palmitate-bound albumin-induced $\mathrm{BiP}$ induction was reduced. These results indicate that the IRE1 $\alpha$-associated induction of a molecular chaperone plays an essential role in protecting PTCs against proteinuria.

\section{Supplementation with the Exogenous Chemical Chaperone TUDCA Ameliorates Age-Related Exacerbation of Proteinuria-Induced PTC Damage}

To confirm the therapeutic potency of an exogenous chemical chaperone on proteinuria-induced PTC damage, even in aged kidneys lacking adaptive UPR, we examined the
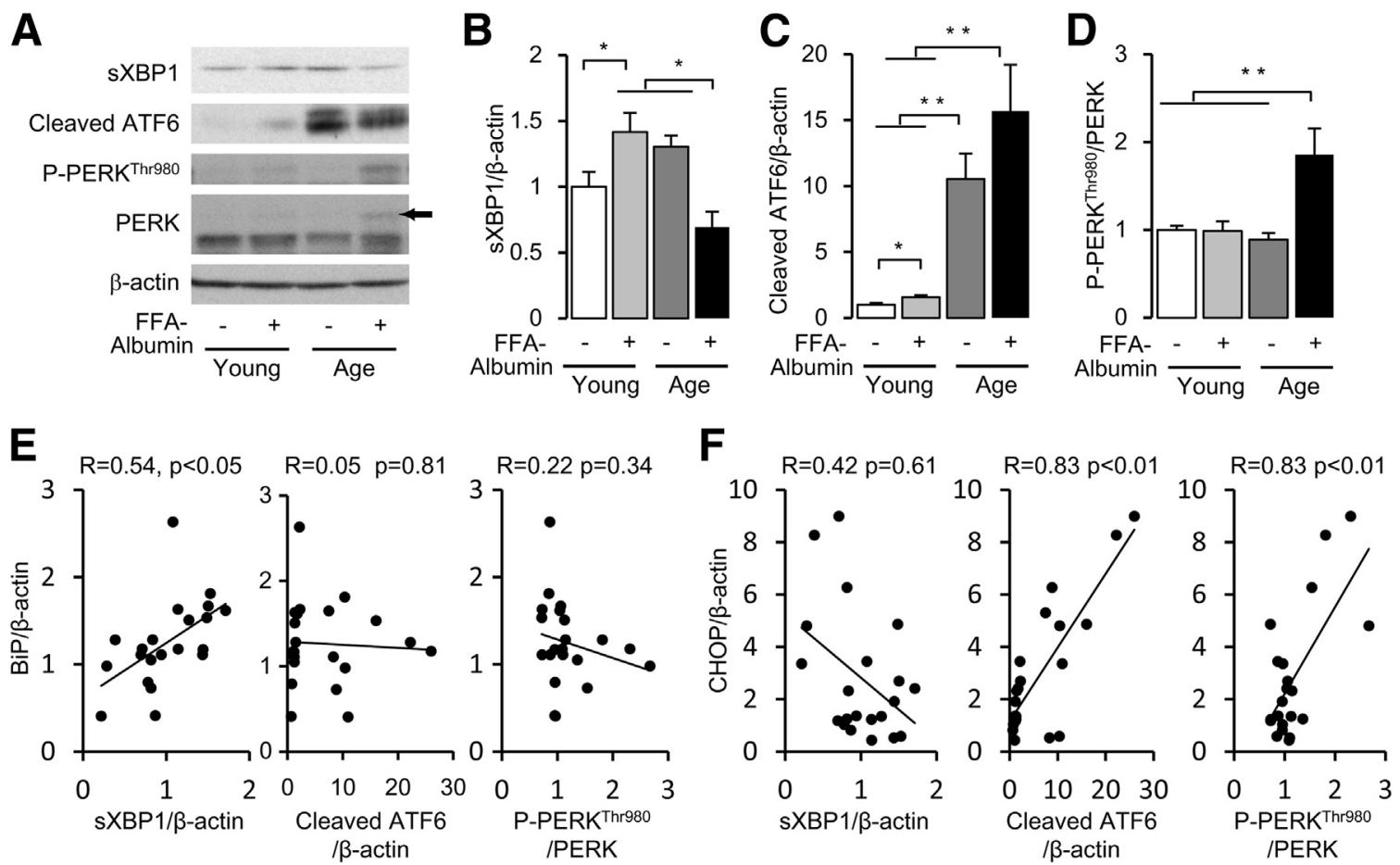

Figure 3 Differential activation of the three branches of the UPR (IRE1 $\alpha$, ATF6, and PERK) in PTCs of aged mice. A: Representative immunoblots of spliced XBP1 (sXBP1), cleaved ATF6, phosphorylated PERK ${ }^{\text {Thr980 }}$, and PERK in protein samples from kidneys of each group of mice, with $\beta$-actin as the internal loading control. Activated phosphorylated PERK is indicated by an arrow. B-D: Quantitative analysis of the ratios to $\beta$-actin of sXBP1 (B) and cleaved ATF6 (C), and of phosphorylated PERK ${ }^{\text {Thr980 }}$ to PERK (D). E and F: Correlation between BiP (E) and CHOP (F) expression levels and the activity of the three UPR pathways, as indicated by spliced XBP1, cleavage of ATF6, and phosphorylation of PERK. Data are expressed as means \pm SEM (B-C) or as scatterplot and regression line (E and $\mathbf{F}) .{ }^{*} P<0.05,{ }^{*} P<0.01$. 
A

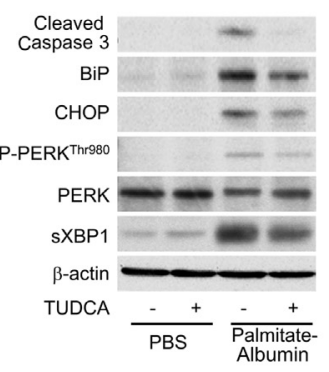

E
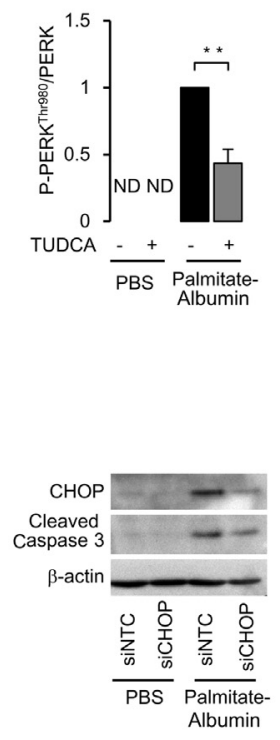

B

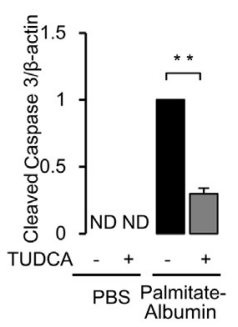

F

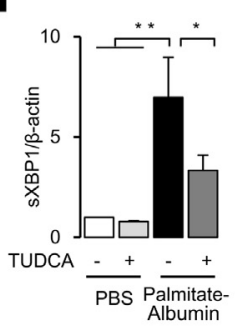

M

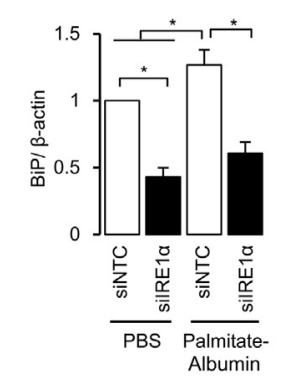

J

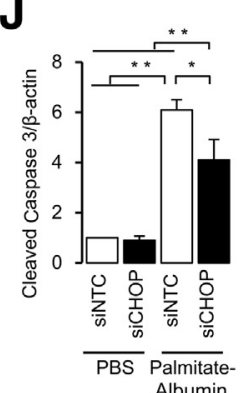

C

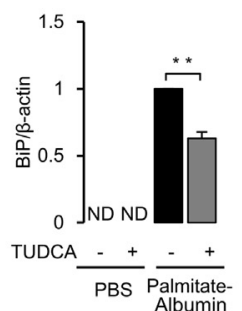

G

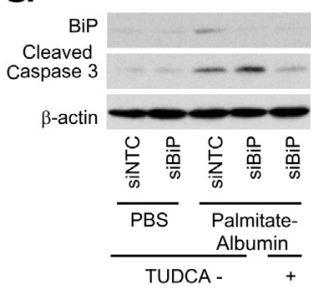

H

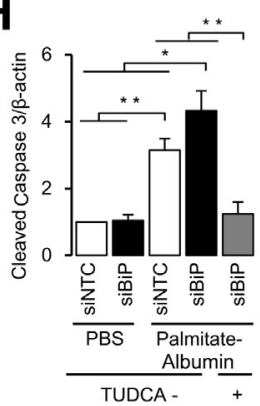

L

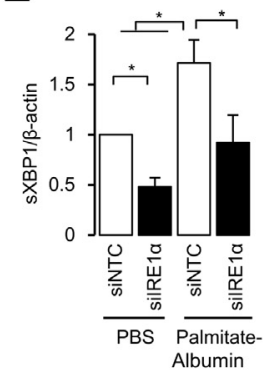

K

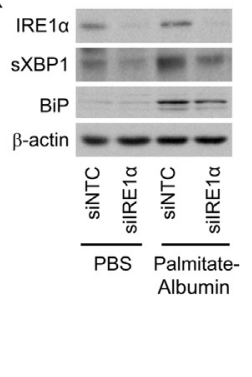

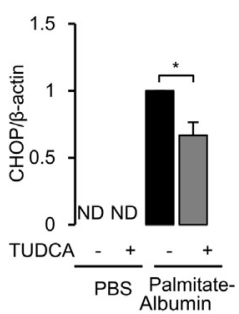

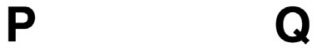

O

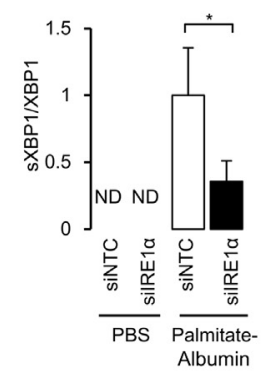

Q

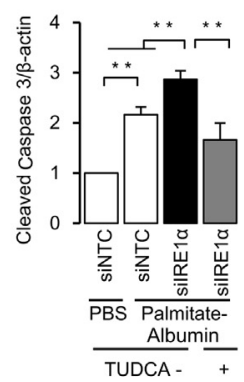

Figure 4 Balance between BiP and CHOP expression is associated with the fate of cultured PTCs exposed to palmitate-bound albumin. A: Representative immunoblots of cleaved caspase 3, BiP, CHOP, phosphorylated PERK ${ }^{\text {Thr980 }}$, PERK, sXBP1, and $\beta$-actin in cultured PTCs stimulated with palmitate-bound albumin, with $\beta$-actin as the internal loading control. B-F: Quantitative analysis of the ratios of cleaved caspase 3 (B), BiP (C), and CHOP (D) to $\beta$-actin, of phosphorylated PERK ${ }^{\text {Thr980 }}$ to PERK (E), and of sXBP1 to $\beta$-actin $(\mathbf{F})(n=4$ each). G: Representative immunoblots of BiP and cleaved caspase 3 in cultured PTCs transfected with nonspecific siRNA (siNTC) and BiP-specific siRNA (siBiP). Cells were stimulated with palmitate-bound albumin with or without pretreatment with TUDCA. H: Quantitative analysis of the ratio of cleaved caspase 3 to $\beta$-actin $(n=4)$. I: Representative immunoblots of CHOP and cleaved caspase 3 in cultured PTCs transfected with siNTC and CHOP-specific siRNA (siCHOP). Cells were stimulated with palmitate-bound albumin. J: Quantitative analysis of the ratio of cleaved caspase 3 to $\beta$-actin $(n=4)$. K: Representative immunoblots of IRE1 $\alpha$, sXBP1, and BiP in cultured PTCs transfected with siNTC and IRE1 $\alpha$ specific siRNA (siIRE1 $\alpha$ ). Cells were stimulated with palmitate-bound albumin. $\mathbf{L}$ and $\mathbf{M}$ : Quantitative analysis of the ratios to $\beta$-actin of sXBP1 (L) and BiP (M) $(n=4$ each). N: Representative blots showing PCR products of spliced and unspliced XBP1 in cultured PTCs transfected with siNTC and siIRE1 $\alpha$. Cells were stimulated with palmitate-bound albumin. 0: Quantitative analysis of the ratio of spliced to unspliced XBP1 $(n=4)$. P: Representative immunoblots of cleaved caspase 3 in cultured PTCs transfected with siNTC and siIRE1 $\alpha$. Q: Quantitative analysis of the ratio of cleaved caspase 3 to $\beta$-actin $(n=6)$. Data are expressed as means \pm SEM. ${ }^{*} P<0.05,{ }^{*} P<0.01$. ND, not detectable. 
effects of TUDCA on FFA-albumin overload-induced PTC damage in aged mice. TUDCA treatment had no effect on body weight, kidney weight, plasma FFA, blood glucose concentrations, and urinary protein excretion in aged mice (Supplemental Table S1). Both age-dependent exacerbation of PTC damage, as determined histologically, and the expression of Ngal and kidney injury molecule-1 (Kim-1) mRNAs were significantly ameliorated by TUDCA treatment (Figure 5, $\mathrm{A}-\mathrm{D})$. No age-dependent increase in proteinuria-induced renal dysfunction, as indicated by serum cystatin $\mathrm{C}$ concentration, was found in aged mice treated with TUDCA (Figure 5E). TUDCA significantly inhibited the FFA-albumin overload-induced increase in apoptosis, as indicated by TUNEL staining (Figure 5, A and B) and cleavage of caspase 3 (Figure 5, $\mathrm{F}$ and $\mathrm{H}$ ). In addition, no age-dependent increase in CHOP expression was observed in aged kidneys treated with TUDCA (Figure 5, G and $\mathrm{H}$ ). These results suggest that supplementation with an exogenous molecular chaperone may have therapeutic efficacy for age-related exacerbation of proteinuria-induced interstitial lesions.

Proteinuria-Related BiP Induction Is Diminished in the Kidneys of Elderly Patients with Persistent Proteinuria

Last, we measured $\mathrm{BiP}$ expression levels in renal biopsy specimens obtained from young adult patients with or without overt proteinuria and from elderly patients with overt proteinuria (Supplemental Table S2). In young adult patients with low-grade proteinuria $(<0.5 \mathrm{~g} / \mathrm{gCre})$, no $\mathrm{BiP}$ induction was observed in the PTCs, as characterized by LTL-positive tubules ${ }^{31}$ (Figure 6, A and B). In contrast, proteinuria induction of $\mathrm{BiP}$ was observed in PTCs from kidney sections of young adults with overt proteinuria $(>1.0$ $\mathrm{g} / \mathrm{gCre}$ ), but not in the PTCs of kidneys from elderly
A

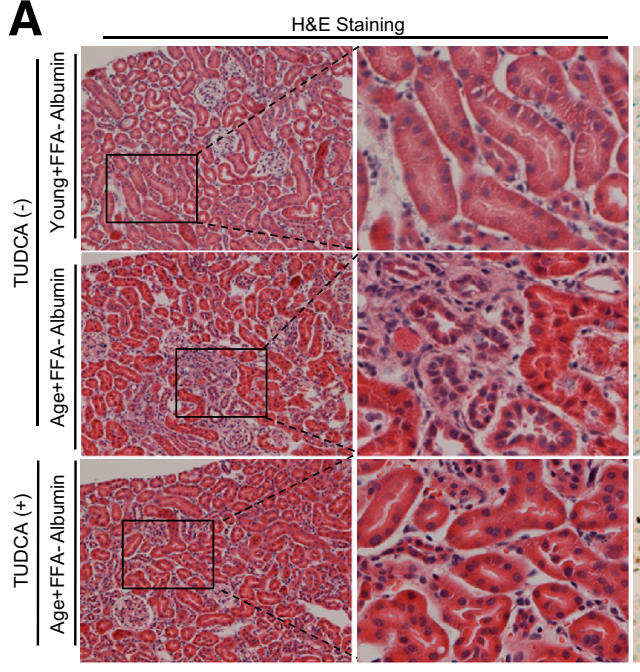

TUNEL Staining
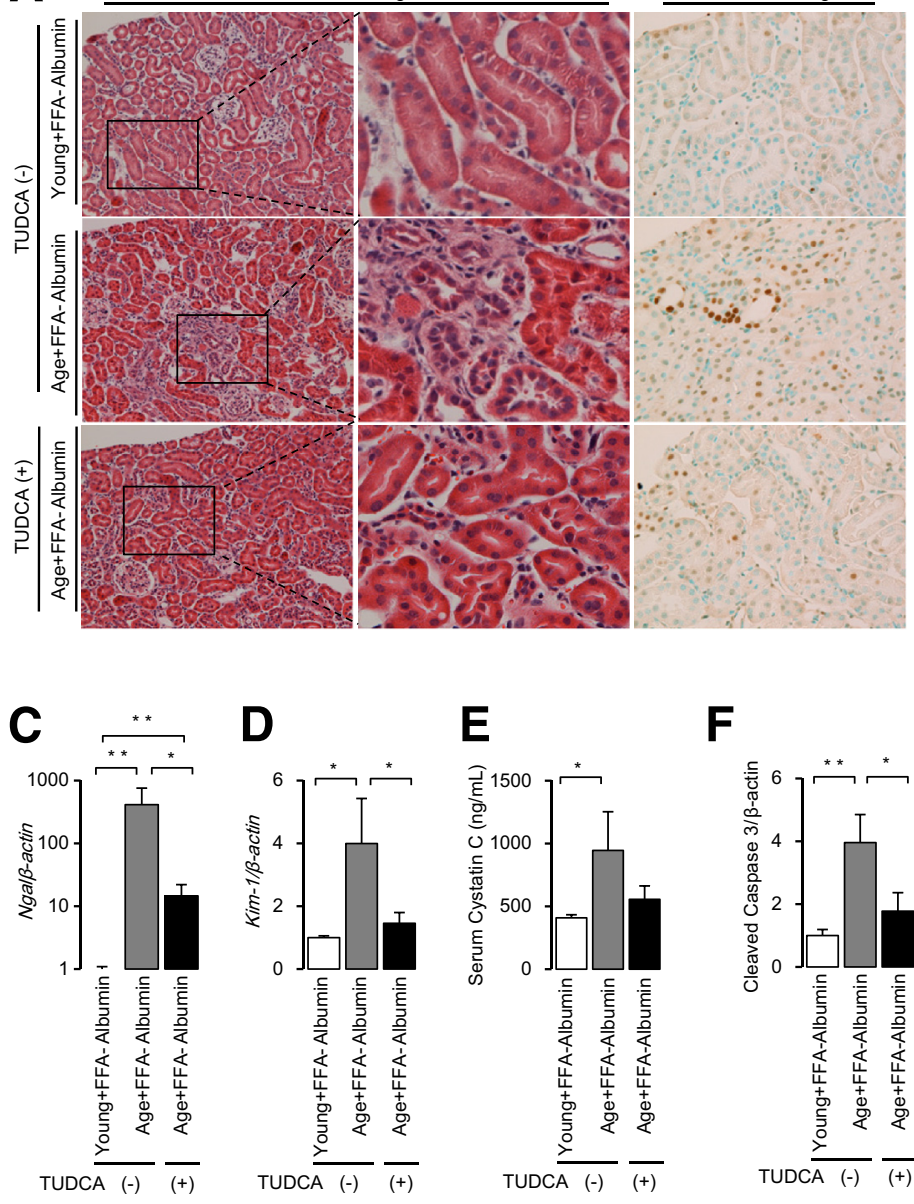

D

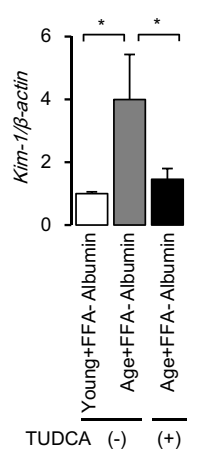

E

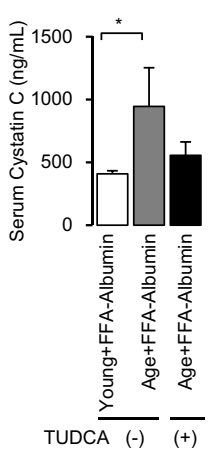

$\mathbf{F}$

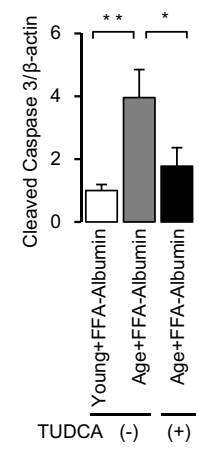

B
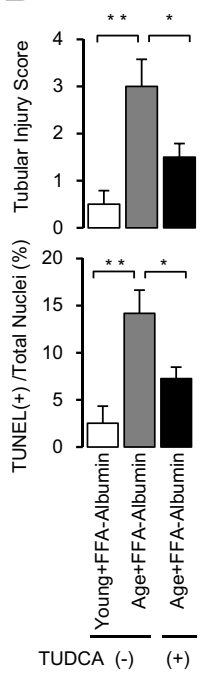

G

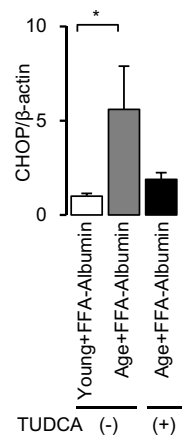

Figure 5 Treatment with the exogenous chemical chaperone TUDCA attenuates age-related exacerbation of proteinuria-induced PTC damage and apoptosis in mice. A: Representative H\&E and TUNEL staining of kidney sections from Young+FFA-albumin mice $(n=6)$, Age+FFAalbumin mice $(n=4)$, and aged mice pretreated with TUDCA and injected with FFA-bound albumin $($ Age+FFA-albumin+TUDCA $)(n=4)$. Boxed regions correspond to the enlarged images in the next column. B: Tubular injury scores of H\&Estained kidney sections and TUNEL-positive cell numbers from the same three groups of mice. $C$ and D: Expression of Ngal (C) and Kim-1 (D) mRNAs in kidney cortex samples from the three groups of mice. E: Serum cystatin C concentrations in the three group of mice. $\mathbf{F}$ and $\mathbf{G}$ : Quantitative analysis of the ratios to $\beta$-actin of cleaved caspase $3(\mathbf{F})$ and CHOP (G). Data are expressed as means \pm SEM. H: Representative immunoblots of cleaved caspase 3 and $\mathrm{CHOP}$ in proteins extracted from kidney cortex samples of the three groups of mice, with $\beta$-actin as the internal loading control. ${ }^{*} P<0.05,{ }^{*} P>$ 0.01 . Original magnification, $\times 200$.

H

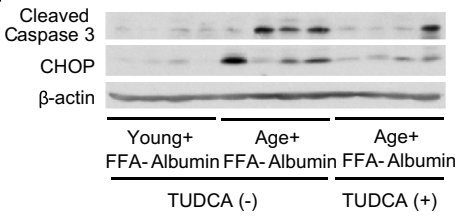


patients, despite their having overt proteinuria $(>1.0 \mathrm{~g} /$ gCre) (Figure 6, A and B). BiP expression was abundant in LTL-negative tubules, regardless of age and the occurrence of proteinuria (Figure 6, A and C).

\section{Discussion}

The present results indicate that adaptive UPR with adequate chaperone induction is required to protect PTCs from
A$$
\text { A }
$$

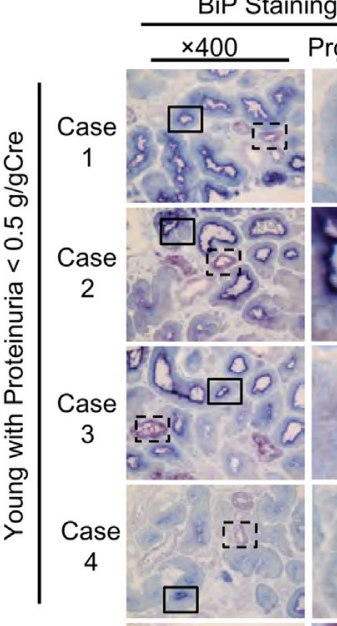


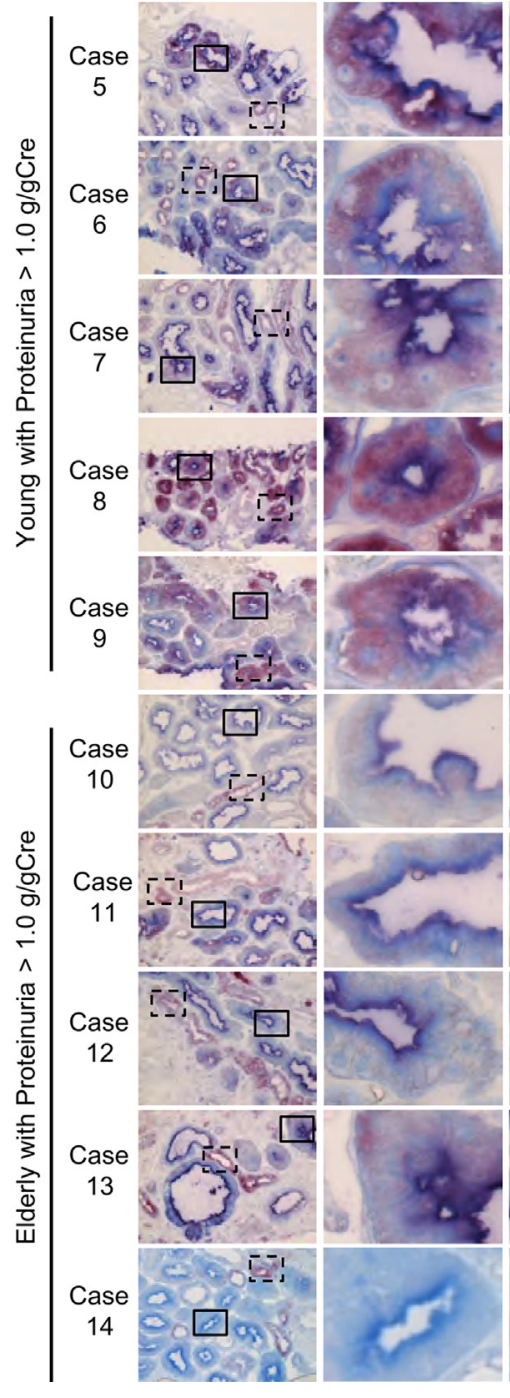

Negative Control $\frac{\mathrm{LTL} \text { (blue) }}{\times 400}$
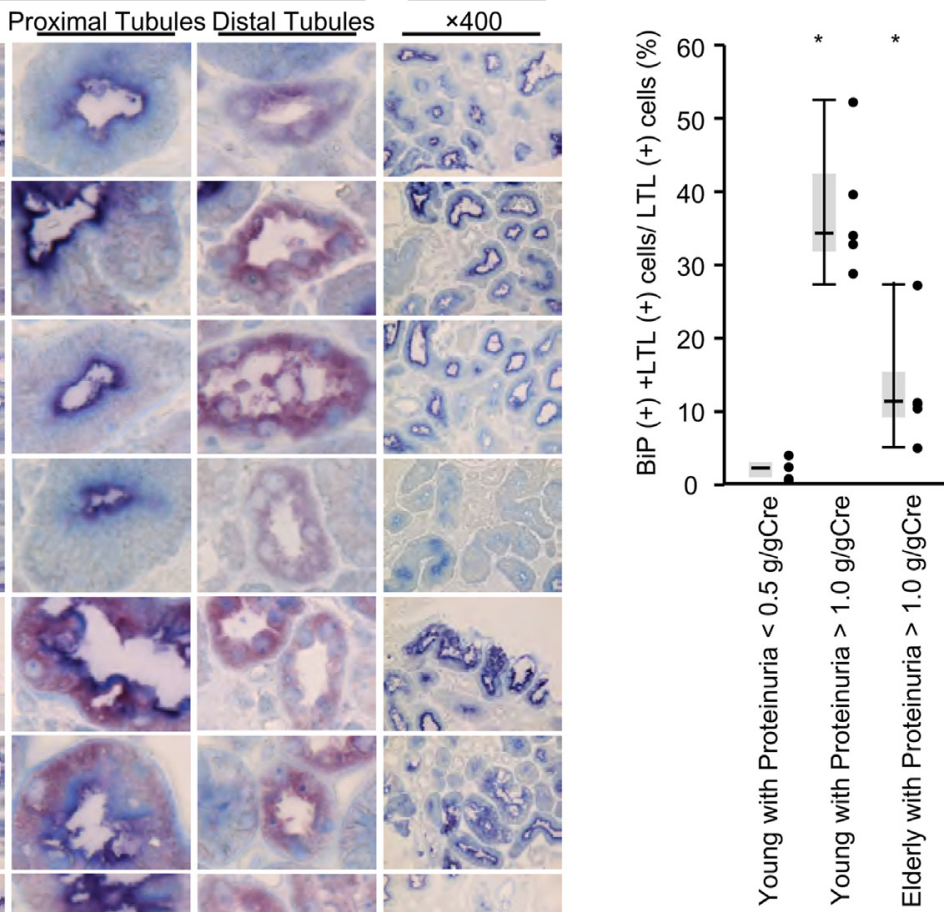

C

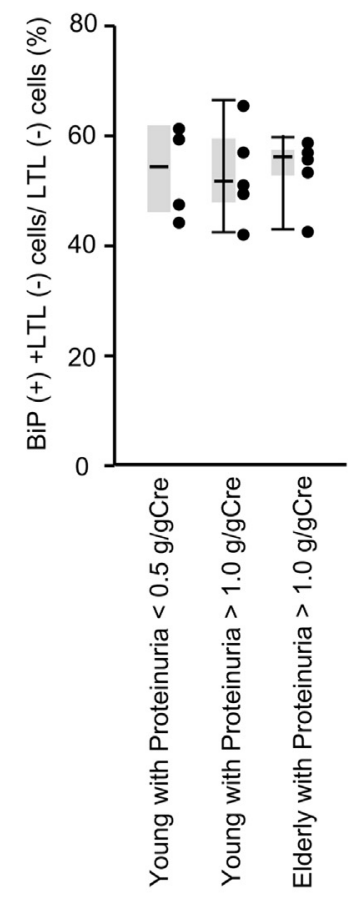

Figure 6 Suppression of proteinuria-related BiP expression in PTCs from kidney sections of elderly patients with overt proteinuria. For negative control staining, kidney sections were stained with only secondary antibody and proximal tubule-specific marker LTL (blue). A: BiP staining (red) in representative renal biopsy samples obtained from young adult patients with low-grade proteinuria $(<0.5 \mathrm{~g} /$ gCre; $n=4)$, young adult patients with high-grade proteinuria (>1.0 g/gCre; $n=5)$, and elderly patients with high-grade proteinuria ( $>1.0 \mathrm{~g} / \mathrm{gCre} ; n$ $=5)$. B and C: Quantitative analyses of the numbers of LTL-positive (B) and LTL-negative (C) cells that were BiP-positive. Data are expressed as scatterplot and boxplot. ${ }^{*} P<0.05$ versus young adult patients with low-grade proteinuria. Original magnification, $\times 400$. 


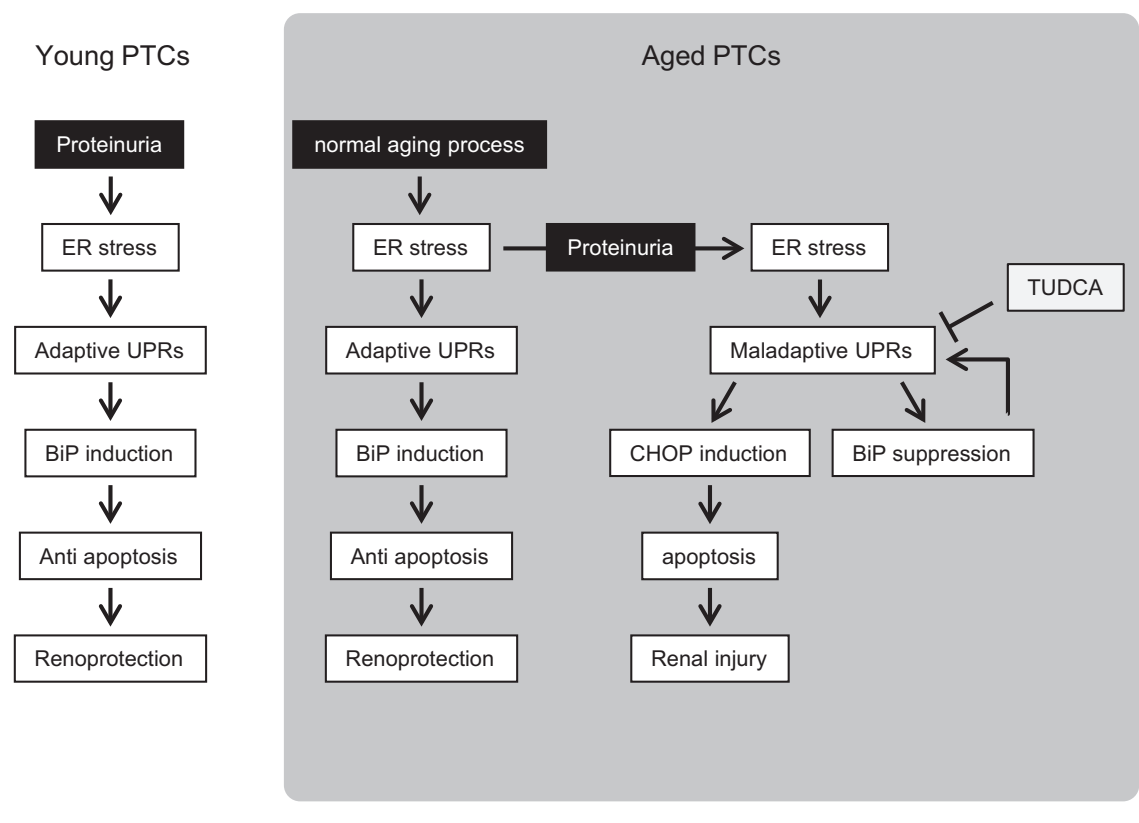

Figure 7 Schematic representation of the mechanism underlying age-related exacerbation of proteinuria-induced PTC damage. Normal PTCs in young kidney have sufficient adaptive UPR capacity to cope with proteinuria. In contrast, aged kidneys require the UPR to maintain basal renal function even in the absence of proteinuria, leading to an insufficient UPR capacity to respond to proteinuria and subsequent maladaptive UPR with CHOP induction. Maladaptive UPR exacerbates PTC apoptosis and severe renal injury. Supplementation with the exogenous chemical chaperone TUDCA ameliorates renal injury associated with maladaptive UPR in aged kidneys. proteinuria-induced cytotoxicity. Normal PTCs in young kidneys have sufficient UPR capacity to cope with proteinuria. In contrast, aged kidneys required the UPR to maintain basal renal function, even in the absence of proteinuria, leading to insufficient UPR capacity to cope with proteinuria and subsequent maladaptive UPR with CHOP induction and cell death. Thus, insufficient UPR capacity is likely involved in the mechanism underlying age-dependent cell vulnerability and the exacerbation of proteinuria-induced tubulointerstitial lesions in aged kidneys. Sufficient supplementation with exogenous molecular chaperones may therefore protect PTCs from proteinuria-induced cell damage, even in aged kidneys (Figure 7). The results we have presented here should provide a better understanding of cell vulnerability in aged kidneys.

We also found that ER-related molecular chaperones play an important role in coping with proteinuria-induced nephrotoxicity and normal aging. ER-stress related molecular chaperones have been shown to play cell-protective roles under stress conditions, ${ }^{18,33,34}$ with $\mathrm{BiP}$ found to be central in regulating the UPR and stress resistance. ${ }^{34}$ Our findings confirm that insufficient UPR-related BiP expression, induced by siRNA against BiP, exacerbated proteinuriainduced apoptosis in cultured PTCs. Moreover, mice overexpressing a dominant-negative mutant of $\mathrm{BiP}$ were found to develop severe proteinuria-induced tubulointerstitial lesions. ${ }^{35}$ These findings indicate that proteinuria-induced and aging-induced overexpression of $\mathrm{BiP}$ confer renoprotection on the PTCs, in accord with results showing that stress-responsive $\mathrm{BiP}$ induction is a cellular adaptive mechanism to cope with stress.

The most important finding of the present study was that proteinuria-induced $\mathrm{BiP}$ expression was significantly suppressed in the kidneys of both aged mice and elderly patients. To our knowledge, this is the first report to show impairments of stress-induced UPR in aged kidneys, although age-dependent alterations in the UPR have been reported in other organs, including brain and liver. ${ }^{36-38}$ In addition to $\mathrm{BiP}$ induction having a renoprotective role against proteinuria, the finding that adequate supplementation with exogenous molecular chaperones protected PTCs from proteinuria-induced cell damage even in aged kidneys suggests that the insufficient induction of BiP may be involved in the age-dependent exacerbation of proteinuria-induced PTC damage. Adaptive UPR may play a renoprotective role in other animal experimental models, including those of acute kidney injury. ${ }^{39,40}$ The increasing incidence of acute kidney injury in elderly patients has become an important clinical problem. ${ }^{41}$ If age-dependent maladaptation of the UPR in PTCs is also associated with higher risks of acute kidney injury, supplementation with exogenous molecular chaperones may serve as a new preventive therapy for acute kidney injury in elderly patients.

Our findings suggest that the age-related decline of $\mathrm{BiP}$ induction may be mediated by impairment of the IRE1 $\alpha$ XBP1 pathway in the PTCs of aged kidneys. BiP induction may be regulated by the activation of three independent UPR pathways (ie, the IRE1 $\alpha$, ATF6, and PERK pathways). ${ }^{42}$ Only the IRE $\alpha-$ XBP1 pathway was impaired in aged kidneys, and its activity was positively associated with $\mathrm{BiP}$ expression levels, which suggests that this pathway is crucial for the maintenance of $\mathrm{BiP}$ induction in PTCs exposed to proteinuria. Interestingly, the IRE1 $\alpha$ pathway is conserved in all eukaryotic organisms, whereas the other two pathways are conserved only in metazoan organisms. ${ }^{43,44}$ Moreover, deletion of the XBP1 pathway without alteration of the other two UPR pathways was sufficient to 
induce age-related diseases, including diabetes. ${ }^{20}$ Results from a unilateral ureteral obstruction kidney disease model showed that the expression of XBP1 protein in PTCs was significantly decreased during prolonged stress conditions and led to fibrosis. ${ }^{45}$ Thus, of the three UPR pathways, the IRE1 $\alpha$-XBP1 pathway may be essential in inducing stressresponsive molecular chaperones in PTCs.

Adaptive UPR leading to an expanded protein folding capacity is essential in protecting cells from cytotoxic stress. ${ }^{18,33,34}$ In contrast, prolonged or insufficient UPR leads to apoptotic cell death under some conditions. ${ }^{46}$ In the present study, the IRE1 $\alpha$-XBP1 pathway was disrupted in the kidneys of aged mice with proteinuria, and the activities of the other two pathways and the expression levels of the proapoptotic transcriptional factor CHOP were markedly and coordinately increased. Thus, hyperactivation of these two pathways may be involved in the mechanism underlying ER stress-related apoptosis in aged kidneys, whereas the IRE1 $\alpha$ pathway is essential for stress-responsive induction of $\mathrm{BiP}$ in the kidneys. However, additional studies are needed to determine the differential mechanisms responsible for such cell-specific and stress-specific regulation of the three independent UPR pathways.

The principal therapeutic goal in glomerular diseases is to reduce urinary albumin/protein excretion. High-grade proteinuria is actually not typical of normal aging in kidneys. Because achievement of this therapeutic goal may be difficult, especially in elderly patients with poorer renal outcomes, ${ }^{47,48}$ new therapeutic concepts are needed to improve renal outcomes in elderly patients with persistent proteinuria. Our results clearly show that aging is associated with worsening of proteinuria-induced tubulointerstitial lesions, suggesting that protecting PTCs from proteinuriainduced cell damage may provide a new therapeutic option in elderly patients with proteinuria. Indeed, supplementation with exogenous molecular chaperones to protect PTCs was effective in aged mice. Because age-related exacerbation of proteinuria-induced renal damage likely involve molecular mechanisms in addition to impaired UPR, efforts to identify these other mechanisms may contribute to improved renal outcomes in elderly patients with proteinuria and thus to improved healthy life expectancy in an aging society.

In conclusion, proteinuria-induced adaptive UPR in PTCs is diminished by aging and is associated with the exacerbation of proteinuria-induced tubulointerstitial lesions in aged kidneys. Enhanced expression of molecular chaperones may provide a new therapeutic strategy in elderly patients with persistent proteinuria.

\section{Acknowledgments}

We thank Makiko Sera and Masako Kanaya and the Central Research Laboratory of the Shiga University of Medical Science for technical assistance and Dr. Takeshi Sugaya
(St. Marianna University School of Medicine, Kanagawa, Japan) for providing mouse PTCs (mProx24).

\section{Supplemental Data}

Supplemental material for this article can be found at http://dx.doi.org/10.1016/j.ajpath.2013.05.026.

\section{References}

1. Fuchs VR: Major trends in the U.S. health economy since 1950. N Engl J Med 2012, 366:973-977

2. Jassal SV, Watson D: Dialysis in late life: benefit or burden. Clin J Am Soc Nephrol 2009, 4:2008-2012

3. Kurella Tamura M, Covinsky KE, Chertow GM, Yaffe K, Landefeld CS, McCulloch CE: Functional status of elderly adults before and after initiation of dialysis. N Engl J Med 2009, 361: $1539-1547$

4. Calabrese V, Cornelius C, Dinkova-Kostova AT, Iavicoli I, Di Paola R, Koverech A, Cuzzocrea S, Rizzarelli E, Calabrese EJ: Cellular stress responses, hormetic phytochemicals and vitagenes in aging and longevity. Biochim Biophys Acta 2012, 1822:753-783

5. Salminen A, Kaarniranta K: ER stress and hormetic regulation of the aging process. Ageing Res Rev 2010, 9:211-217

6. Cattran D: Management of membranous nephropathy: when and what for treatment. J Am Soc Nephrol 2005, 16:1188-1194

7. Iseki K, Ikemiya Y, Iseki C, Takishita S: Proteinuria and the risk of developing end-stage renal disease. Kidney Int 2003, 63:1468-1474

8. Nicola LD, Minutolo R, Chiodini P, Borrelli S, Zoccali C, Postorino M, Iodice C, Nappi F, Fuiano G, Gallo C, Conte G; Italian Society of Nephrology Study Group Target Blood pressure Levels (TABLE) in CKD: The effect of increasing age on the prognosis of non-dialysis patients with chronic kidney disease receiving stable nephrology care. Kidney Int 2012, 82:482-488

9. Hetz C: The unfolded protein response: controlling cell fate decisions under ER stress and beyond. Nat Rev Mol Cell Biol 2012, 13: 89-102

10. Wang S, Kaufman RJ: The impact of the unfolded protein response on human disease. J Cell Biol 2012, 197:857-867

11. Hotamisligil GS: Endoplasmic reticulum stress and the inflammatory basis of metabolic disease. Cell 2010, 140:900-917

12. Bertolotti A, Zhang Y, Hendershot LM, Harding HP, Ron D: Dynamic interaction of $\mathrm{BiP}$ and $\mathrm{ER}$ stress transducers in the unfolded-protein response. Nat Cell Biol 2000, 2:326-332

13. Oikawa D, Kimata Y, Kohno K, Iwawaki T: Activation of mammalian IRE1alpha upon ER stress depends on dissociation of BiP rather than on direct interaction with unfolded proteins. Exp Cell Res 2009, 315: 2496-2504

14. Marciniak SJ, Yun CY, Oyadomari S, Novoa I, Zhang Y, Jungreis R, Nagata K, Harding HP, Ron D: CHOP induces death by promoting protein synthesis and oxidation in the stressed endoplasmic reticulum. Genes Dev 2004, 18:3066-3077

15. Song B, Scheuner D, Ron D, Pennathur S, Kaufman RJ: Chop deletion reduces oxidative stress, improves beta cell function, and promotes cell survival in multiple mouse models of diabetes. J Clin Invest 2008, 118: 3378-3389

16. Zinszner H, Kuroda M, Wang X, Batchvarova N, Lightfoot RT, Remotti H, Stevens JL, Ron D: CHOP is implicated in programmed cell death in response to impaired function of the endoplasmic reticulum. Genes Dev 1998, 12:982-995

17. Bailly-Maitre B, Fondevila C, Kaldas F, Droin N, Luciano F, Ricci JE, Croxton R, Krajewska M, Zapata JM, Kupiec-Weglinski JW, Farmer D, Reed JC: Cytoprotective gene BI-1 is required for intrinsic 
protection from endoplasmic reticulum stress and ischemia-reperfusion injury. Proc Natl Acad Sci USA 2006, 103:2809-2814

18. Bando Y, Tsukamoto Y, Katayama T, Ozawa K, Kitao Y, Hori O, Stern DM, Yamauchi A, Ogawa S: ORP150/HSP12A protects renal tubular epithelium from ischemia-induced cell death. FASEB J 2004, 18:1401-1403

19. Kuznetsov G, Bush KT, Zhang PL, Nigam SK: Perturbations in maturation of secretory proteins and their association with endoplasmic reticulum chaperones in a cell culture model for epithelial ischemia. Proc Natl Acad Sci USA 1996, 93:8584-8589

20. Lindenmeyer MT, Rastaldi MP, Ikehata M, Neusser MA, Kretzler M, Cohen CD, Schlöndorff D: Proteinuria and hyperglycemia induce endoplasmic reticulum stress. J Am Soc Nephrol 2008, 19:2225-2236

21. Nakajo A, Khoshnoodi J, Takenaka H, Hagiwara E, Watanabe T, Kawakami H, Kurayama R, Sekine Y, Bessho F, Takahashi S, Swiatecka-Urban A, Tryggvason K, Yan K: Mizoribine corrects defective nephrin biogenesis by restoring intracellular energy balance. J Am Soc Nephrol 2007, 18:2554-2564

22. Ohse T, Inagi R, Tanaka T, Ota T, Miyata T, Kojima I, Ingelfinger JR, Ogawa S, Fujita T, Nangaku M: Albumin induces endoplasmic reticulum stress and apoptosis in renal proximal tubular cells. Kidney Int 2006, 70:1447-1455

23. Tanaka Y, Kume S, Araki S, Isshiki K, Chin-Kanasaki M, Sakaguchi M, Sugimoto T, Koya D, Haneda M, Kashiwagi A, Maegawa H, Uzu T: Fenofibrate, a PPARalpha agonist, has renoprotective effects in mice by enhancing renal lipolysis. Kidney Int 2011, 79:871-882

24. Kume S, Uzu T, Horiike K, Chin-Kanasaki M, Isshiki K, Araki S, Sugimoto T, Haneda M, Kashiwagi A, Koya D: Calorie restriction enhances cell adaptation to hypoxia through Sirt1-dependent mitochondrial autophagy in mouse aged kidney. J Clin Invest 2010, 120: $1043-1055$

25. Xie Y, Luo J, Kennedy S, Davidson NO: Conditional intestinal lipotoxicity in Apobec-1-/- Mttp-IKO mice: a survival advantage for mammalian intestinal apolipoprotein B mRNA editing. J Biol Chem 2007, 282:33043-33051

26. Zhou L, Liu M, Zhang J, Chen H, Dong LQ, Liu F: DsbA-L alleviates endoplasmic reticulum stress-induced adiponectin downregulation. Diabetes 2010, 59:2809-2816

27. Koyama T, Kume S, Koya D, Araki S, Isshiki K, Chin-Kanasaki M, Sugimoto T, Haneda M, Sugaya T, Kashiwagi A, Maegawa H, Uzu T: SIRT3 attenuates palmitate-induced ROS production and inflammation in proximal tubular cells. Free Radic Biol Med 2011, $51: 1258-1267$

28. Soumura M, Kume S, Isshiki K, Takeda N, Araki S, Tanaka Y, Sugimoto T, Chin-Kanasaki M, Nishio Y, Haneda M, Koya D, Kashiwagi A, Maegawa H, Uzu T: Oleate and eicosapentaenoic acid attenuate palmitate-induced inflammation and apoptosis in renal proximal tubular cell. Biochem Biophys Res Commun 2010, 402: 265-271

29. Yang X, Kume S, Tanaka Y, Isshiki K, Araki S, Chin-Kanasaki M, Sugimoto T, Koya D, Haneda M, Sugaya T, Li D, Han P, Nishio Y, Kashiwagi A, Maegawa H, Uzu T: GW501516, a PPARdelta agonist, ameliorates tubulointerstitial inflammation in proteinuric kidney disease via inhibition of TAK1-NFkappaB pathway in mice. PLoS One 2011, 6:e25271

30. Guo W, Wong S, Xie W, Lei T, Luo Z: Palmitate modulates intracellular signaling, induces endoplasmic reticulum stress, and causes apoptosis in mouse 3T3-L1 and rat primary preadipocytes. Am J Physiol Endocrinol Metab 2007, 293:E576-E586
31. D'Agati V, Trudel M: Lectin characterization of cystogenesis in the SBM transgenic model of polycystic kidney disease. J Am Soc Nephrol 1992, 3:975-983

32. Kamijo Y, Hora K, Kono K, Takahashi K, Higuchi M, Ehara T, Kiyosawa K, Shigematsu H, Gonzalez FJ, Aoyama T: PPARalpha protects proximal tubular cells from acute fatty acid toxicity. J Am Soc Nephrol 2007, 18:3089-3100

33. Feder ME, Hofmann GE: Heat-shock proteins, molecular chaperones, and the stress response: evolutionary and ecological physiology. Annu Rev Physiol 1999, 61:243-282

34. Morris JA, Dorner AJ, Edwards CA, Hendershot LM, Kaufman RJ: Immunoglobulin binding protein $(\mathrm{BiP})$ function is required to protect cells from endoplasmic reticulum stress but is not required for the secretion of selective proteins. J Biol Chem 1997, 272 : 4327-4334

35. Kimura K, Jin H, Ogawa M, Aoe T: Dysfunction of the ER chaperone $\mathrm{BiP}$ accelerates the renal tubular injury. Biochem Biophys Res Commun 2008, 366:1048-1053

36. Naidoo N, Ferber M, Master M, Zhu Y, Pack AI: Aging impairs the unfolded protein response to sleep deprivation and leads to proapoptotic signaling. J Neurosci 2008, 28:6539-6548

37. Nuss JE, Choksi KB, DeFord JH, Papaconstantinou J: Decreased enzyme activities of chaperones PDI and BiP in aged mouse livers. Biochem Biophys Res Commun 2008, 365:355-361

38. Rabek JP, Boylston WH 3rd, Papaconstantinou J: Carbonylation of ER chaperone proteins in aged mouse liver. Biochem Biophys Res Commun 2003, 305:566-572

39. Inagi R, Kumagai $T$, Nishi H, Kawakami $T$, Miyata $T$, Fujita $T$, Nangaku M: Preconditioning with endoplasmic reticulum stress ameliorates mesangioproliferative glomerulonephritis. J Am Soc Nephrol 2008, 19:915-922

40. Prachasilchai W, Sonoda H, Yokota-Ikeda N, Oshikawa S, Aikawa C, Uchida K, Ito K, Kudo T, Imaizumi K, Ikeda M: A protective role of unfolded protein response in mouse ischemic acute kidney injury. Eur J Pharmacol 2008, 592:138-145

41. Chronopoulos A, Cruz DN, Ronco C: Hospital-acquired acute kidney injury in the elderly. Nat Rev Nephrol 2010, 6:141-149

42. Takayanagi S, Fukuda R, Takeuchi Y, Tsukada S, Yoshida K: Gene regulatory network of unfolded protein response genes in endoplasmic reticulum stress. Cell Stress Chaperones 2013, 18:11-23

43. Calfon M, Zeng H, Urano F, Till JH, Hubbard SR, Harding HP, Clark SG, Ron D: IRE1 couples endoplasmic reticulum load to secretory capacity by processing the XBP-1 mRNA, [Erratum appeared in Nature 2002, 420:202]. Nature 2002, 415:92-96

44. Patil C, Walter P: Intracellular signaling from the endoplasmic reticulum to the nucleus: the unfolded protein response in yeast and mammals. Curr Opin Cell Biol 2001, 13:349-355

45. Chiang CK, Hsu SP, Wu CT, Huang JW, Cheng HT, Chang YW, Hung KY, Wu KD, Liu SH: Endoplasmic reticulum stress implicated in the development of renal fibrosis. Mol Med 2011, 17: 1295-1305

46. Inagi R: Endoplasmic reticulum stress in the kidney as a novel mediator of kidney injury. Nephron Exp Nephrol 2009, 112: e1-e9

47. Juurlink DN, Mamdani M, Kopp A, Laupacis A, Redelmeier DA: Drug-drug interactions among elderly patients hospitalized for drug toxicity. JAMA 2003, 289:1652-1658

48. Masaki KH, Schatz IJ, Burchfiel CM, Sharp DS, Chiu D, Foley D, Curb JD: Orthostatic hypotension predicts mortality in elderly men: the Honolulu Heart Program. Circulation 1998, 98:2290-2295 